\title{
Surfactant Assisted Stabilization of Carbon Nanotubes Synthesized by a Spray Pyrolysis Method
}

\author{
D. Mendoza-Cachú, ${ }^{1}$ C. Mercado-Zúñiga, ${ }^{2}$ and G. Rosas $^{1}$ \\ ${ }^{1}$ Instituto de Investigaciones Metalúrgicas, UMSNH, Edificio U., Ciudad Universitaria, 58000 Morelia, MICH, Mexico \\ ${ }^{2}$ Tecnológico de Estudios Superiores de Coacalco, Av. 16 de Septiembre No. 54, Col. Cabecera Municipal, \\ 55700 Coacalco de Berriozábal, MEX, Mexico
}

Correspondence should be addressed to D. Mendoza-Cachú; david.mendozach@gmail.com

Received 27 March 2017; Accepted 18 May 2017; Published 2 July 2017

Academic Editor: Mohindar S. Seehra

\begin{abstract}
Copyright (C) 2017 D. Mendoza-Cachú et al. This is an open access article distributed under the Creative Commons Attribution License, which permits unrestricted use, distribution, and reproduction in any medium, provided the original work is properly cited.

Surface modification of carbon nanotubes has been an interesting issue from a composites materials point of view. A nanotubes agglomeration has to be avoided to achieve a homogeneous dispersion in a composite matrix. In this research, we report on the synthesis of carbon nanotubes using a variant of the chemical vapor deposition technique known as spray pyrolysis method. X-ray diffraction (XRD), transmission electron microscopy (TEM), and scanning electron microscopy (SEM) studies showed that the synthesized products had an aligned structure with low purity degree, high content of catalyst particles, and a smaller amount of amorphous carbon. A secondary method was applied, which involves an acidic treatment that dissolves contaminant particles to enhance the purity of the nanotubes. Microstructural analysis, which includes XRD and SEM, indicates an effective reduction of impurities. Dispersion of the nanotubes was assessed using different surfactants, such as sodium dodecyl-sulfate (SDS) and ethylenediaminetetraacetic acid (EDTA). Finally, Raman spectroscopy, UV-Vis, and SEM techniques confirm that better results were obtained with EDTA. For EDTA and SDS surfactants, low concentrations of $0.3 \mathrm{mg} / \mathrm{mL}$ and $0.2 \mathrm{mg} / \mathrm{mL}$ were most efficient, respectively.
\end{abstract}

\section{Introduction}

Since their first appearance in 1991 [1], carbon nanotubes (CNTs) have attracted the scientific attention due to their superior properties, both physical and mechanical. Some features may significantly vary referring to a walled number of the CNTs. For example, its transport properties could be different, and it depends on their structure: chiral, armchair, or zig-zag. The cases of chiral or zig-zag depend on vector index $(n, m)$. If $(n-m) / 3$ ratio is an integer number, the CNTs have metallic character. Besides, if the above ratio is an irrational number the CNTs have semiconductor character. On the armchair structure, all CNTs have a metallic behavior, as $(n, m)$ indexes are always equal, and $(n-m) / 3=0[2,3]$. However, specific studies are necessary to determine the conducting behavior of the multiwalled CNTs (MWCNTs). Different techniques have been addressed to obtain carbon nanostructures, such as arc discharge, plasma spraying, and chemical vapor deposition (CVD) [4-6]. These methods may have a considerable impact on the properties of the CNTs, including but not limited to strength, Young's modulus and high electrical and thermal conductivity [7-10]. Within synthesis techniques, spray pyrolysis, which is a variant of the CVD method, offers certain advantages such as large scales of nanotubes production, surface morphology, packing degree, control over the number of walls and, especially, control of their dimensions [11-14]. There are several similarities between CNTs synthesized by the spray pyrolysis method and conventional CVD process. Both techniques need a catalyst to promote the nanotubes growth. However, differences reside in the form of the catalyst used in each process. Conventional CVD uses a stationary catalyst which leads to the presence of well-aligned CNTs. Spray pyrolysis uses catalytic nanoparticles present in the gas phase that increases randomness in the process of CNTs growth resulting in less alignment, improving nanotubes dispersion. Besides alignment, purity of CNTs is a bigger concern. Thus, poor solubility of precursors and the type of solvents largely affect quality and purity of the 
products. On the other hand, the advantages of the species nebulization in the spray pyrolysis process are its use at an industrial scale and are cheaper than conventional CVD [15, 16]. About purity, catalytic particles and other carbon structures, which are impurities in the CNTs, need a secondary process. Among them, an acidic treatment using different acids, such as $\mathrm{HNO}_{3}$ and $\mathrm{HCl}$, is frequently used $[17,18]$.

The final processing of CNTs is according to their potential applications where two main routes can be found. The first, known as functionalization, involves applying treatment with some compounds or particles (e.g., Ag and Au), which have the capacity to be adsorbed on the CNTs surface, modifying it in such a way that it can perform a particular task. Second, dispersion and stabilization, using surfactant agents, get adsorption to the surface, but in this case, their function is to overcome the electrostatic forces that keep the CNTs attached.

Functionalized carbon nanotubes can be used to improve the CO gas sensing performance, detection, and quantification of polyphenols and other compounds, as well as drugdelivery systems to target cancer diseases [19-22]. On the other hand, dispersed CNTs are preferred as reinforcement in all kinds of matrices (polymers, ceramics, and metals and alloys) to enhance fundamental properties [23-25].

Thus, the present work focuses on the high-purity synthesis, acids purification, and stable dispersion of multiwalled CNTs for their following application as reinforcement material in metallic matrix composites. The synthesis was carried out by the chemical vapor deposition process, while the dispersion of the nanotubes was performed using commercial surfactants. This work is a continuation of a report presented at International Materials Research Congress [26].

\section{Experimental}

The spray pyrolysis technique was used to synthesize the MWCNTs, according to Andrews et al. [27], with minor modifications. First, a solution of ferrocene and toluene (catalyst and carbon precursor, resp.) was prepared. Then this solution was nebulized and fed into a quartz tube, which acts as a substrate in a horizontal hot-wall reactor at $850^{\circ} \mathrm{C}$. The argon flow was maintained for about 40 minutes, so the growth reaction of the nanotubes can be completed.

In order to improve the purity degree, $1 \mathrm{mg}$ of CNTs was mixed with a solution of hydrochloric and nitric acid $(1: 1)$ and kept under stirring for 90 minutes. The nanotubes were filtered and washed with distilled water to remove any waste from the acids.

Sodium dodecyl-sulfate (SDD) and ethylenediaminetetraacetic acid (EDTA) from Sigma-Aldrich were used as surfactant agents to achieve a stable dispersion of the CNTs in $7 \mathrm{~mL}$ of isopropyl alcohol. Then, different amounts of surfactant were added to get concentrations of $0.05 \mathrm{mg}$, $0.10 \mathrm{mg}, 0.20 \mathrm{mg}, 0.30 \mathrm{mg}, 0.50 \mathrm{mg}$, and $0.80 \mathrm{mg}$ of surfactant per milliliter of solvent. One milligram of CNTs was added to the solution and treated with ultrasonic bath for 90 minutes. UV-Vis and Raman spectroscopies (using a Beckman DU20 spectrophotometer and a Bruker Senterra microscope, resp.), scanning electron microscopy (JEOL JSM-6400), and transmission electron microscopy (Philips Tecnai F-20) were used as structural characterization techniques to study the dispersion degree and carbon nanotubes integrity.

\section{Results and Discussion}

3.1. CNTs Synthesis. Figure 1 shows TEM micrographs of the as-synthesized CNTs. Figure 1(a) illustrates a bright field TEM image showing CNTs agglomeration with a high degree of contaminant catalytic particles. Figure 1(b) is a dark field image that shows bright areas belonging to the residual catalytic particles on the CNTs' surface. From an HREM image (Figure 1(c)), multiwalled CNTs are observed with an outer diameter of $20 \mathrm{~nm}$ approximately, with a range from 50 to 55 graphene layers. The HREM image in Figure 1(d) shows a residual iron catalytic particle with interspacing distances corresponding to (110) crystallographic planes of their cubic bcc structure. This type of agglomeration and catalytic nanoparticles contaminant has been widely reported in spray pyrolysis synthesis methods [16].

An XRD study was applied to establish the nature of the contaminant particles as well as the purification treatment efficiency (Figure 2). The corresponding pattern to the assynthesized CNTs is shown in Figure 2(a). Characteristic reflections from the carbon graphitic structure (002), (100), and (101) can be observed, as well as the iron bcc cubic structure (110) planes according to JCPDS 03-065-6212.

Figure 2(b) shows the XRD pattern of the CNTs after the purification treatment. As the $\mathrm{Fe}$ reflections in the Bragg angles reduce, $2 \theta=43^{\circ}$ and $78^{\circ}$, their contamination decreases considerably, although it is still present in minimum amounts. However, because of the considerable amount of $\mathrm{OH}$ groups present during the process, some Fe oxidation is promoted in the form of $\mathrm{FeO}_{2}$.

In addition to the XRD study, a SEM analysis was carried out to evaluate the morphology of the CNTs and the efficiency of the purification treatment. Figures 3(a)3(b) present micrographs at different magnifications of the as-synthesized CNTs showing a high packing degree and a considerable amount of contaminant particles. As shown in Figures 3(c)-3(d), CNTs display a substantial change after purification, especially for the significant reduction of the contaminant particles. The weight percentage of contaminant particles before and after the cleaning process was $6.55 \%$ and $2.49 \%$, respectively, obtained from the EDS analysis, indicating a reduction in the residual Fe particles, products of the synthesis process.

3.2. Dispersion of CNTs Using Different Surfactants. Both compounds SDS and EDTA were studied using the UVVis technique to establish the influence of surfactant nature over the dispersion of CNTs. Figures 4(a)-4(b) correspond to the UV-Vis spectra of the dispersion of CNTs using different concentrations of the surfactants. It can clearly be seen that the characteristic absorption band of the CNTs is found to a wavelength of $\sim 275 \mathrm{~nm}$ [28]. When using EDTA (Figure 4(a)), better results were obtained with a concentration of $0.30 \mathrm{mg} / \mathrm{mL}$; shown by the curve with the 


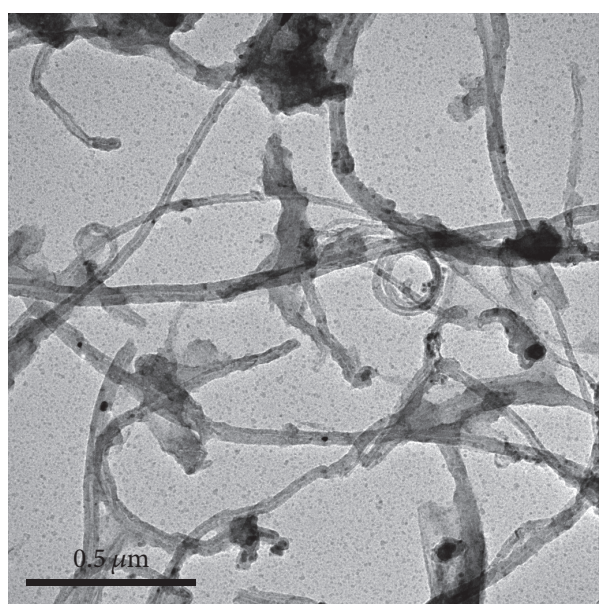

(a)

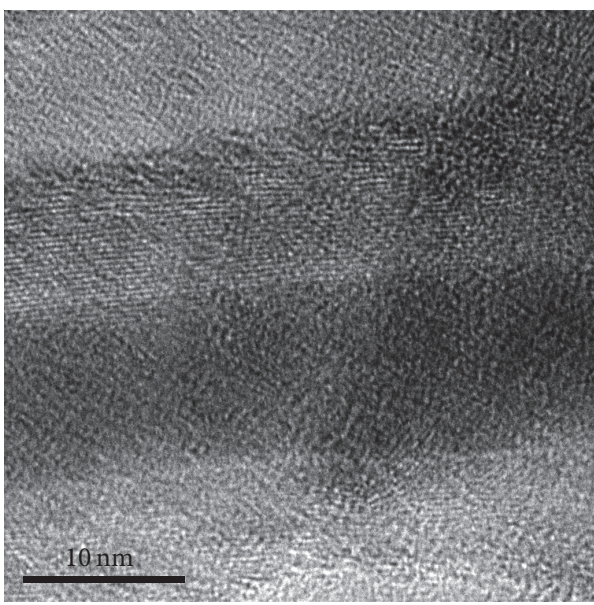

(c)

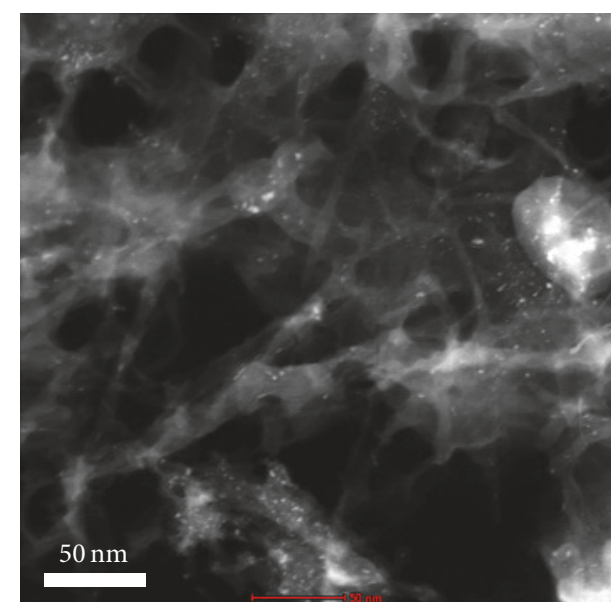

(b)

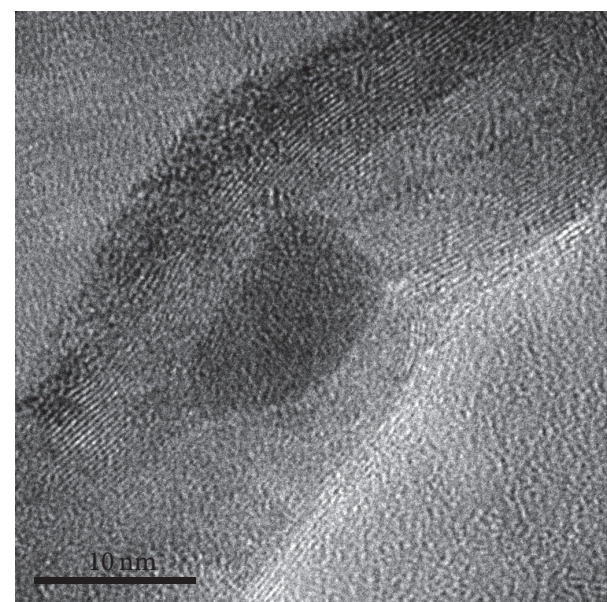

(d)

FIGURE 1: TEM micrographs of the as-synthesized CNTs: (a) bright field image, (b) dark field image, the brightest phase corresponding to residual catalytic particles, (c) HRTEM image showing the presence of MWCNTs, and (d) HRTEM image of the CNTs with Fe particle.

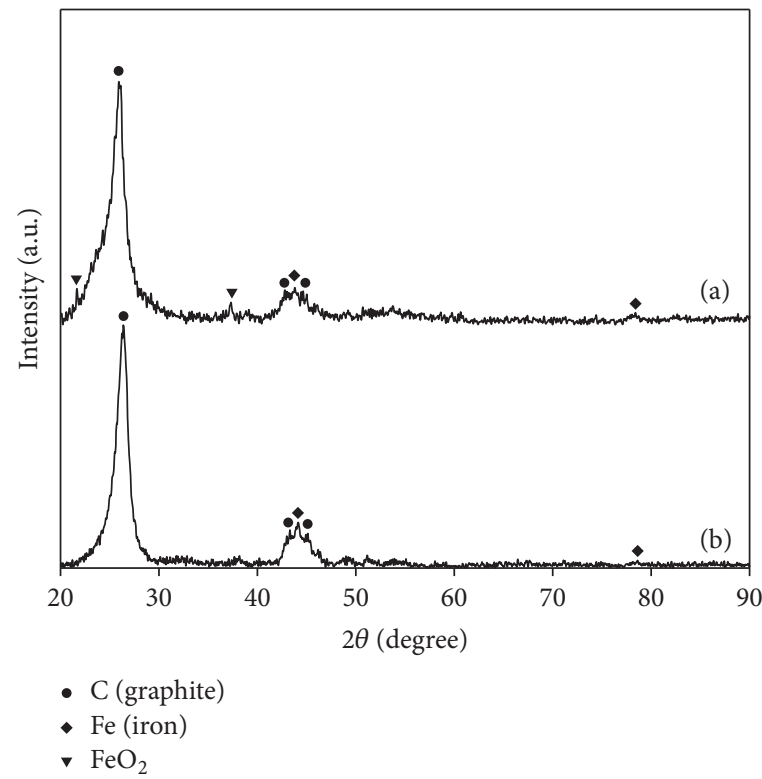

FIGURE 2: XRD patterns of the (a) as-synthesized CNTs and (b) after the acidic treatment. 


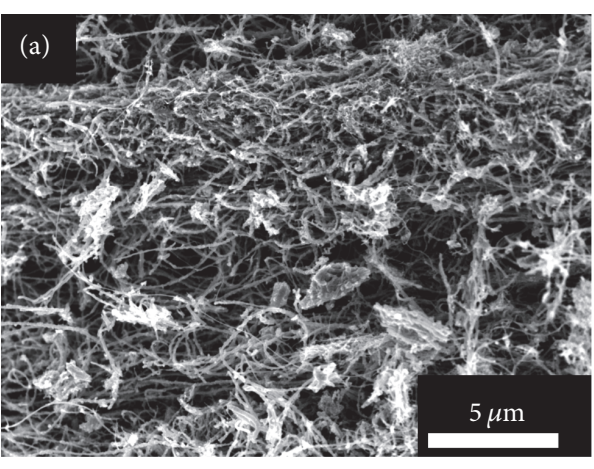

(a)

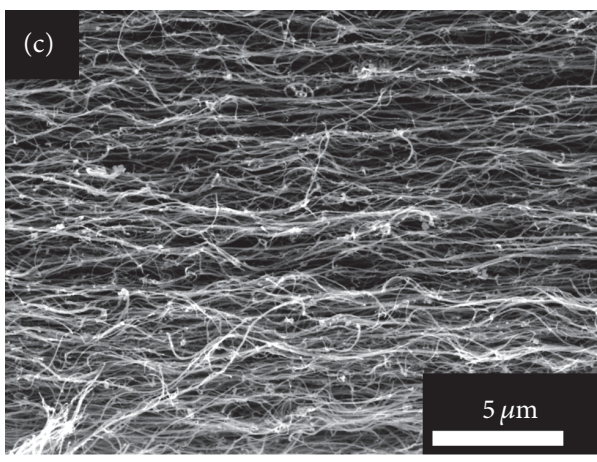

(c)

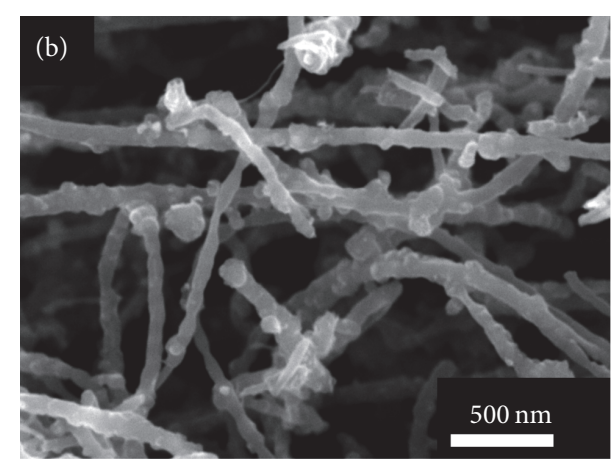

(b)

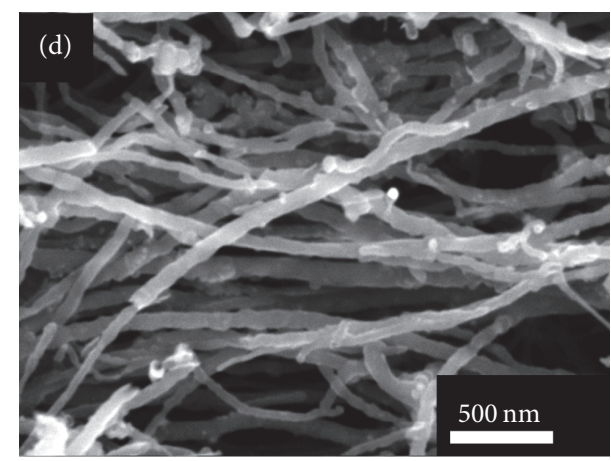

(d)

FIGURE 3: SEM micrographs of CNTs: (a-b) as-synthesized and (c-d) after purification process, at different magnifications.

higher absorbance, this means a larger amount of sample absorbing in this range. In the case of SDS (Figure 4(b)), the better absorption result in the CNTs was observed with a $0.20 \mathrm{mg} / \mathrm{mL}$ concentration, lower than that for the EDTA.

Concentrations from middle to low present good results in dispersing the MWCNTs, as the UV-Vis studies show. Regarding fundamental principles, achieving dispersion is necessary to overcome the Van der Waals forces that act between nanotubes. Surfactants such as SDS and EDTA create energy barriers that prevent further agglomeration. However, when the concentration of molecules reaches a certain value, the surfactant tend to precipitate. This effect is because the end of the chain that is not attached to the CNTs creates an electrostatic field, resulting in the increase of the surfactant chain length that leads to flocculation [29]. Therefore, low concentration of surfactant is desirable to obtain a stable and homogenous dispersion.

Figure 5 presents SEM micrographs of the best results for the dispersion of CNTs using the two different surfactants. Clearly, EDTA was most effective than SDS at achieving a good dispersion of the CNTs (Figure 5(a)). The best dispersion was obtained using an EDTA concentration of $0.30 \mathrm{mg} / \mathrm{mL}$. On the other hand, a SDS concentration of $0.20 \mathrm{mg} / \mathrm{mL}$ (Figure 5(b)) showed the best dispersion results, which is in agreement with the UV-Vis analysis. Different authors have previously reported similar results [30].

Finally, Figure 6 shows the Raman spectra of CNTs at different stages of the process to which they were subjected: (a) CNTs as-synthesized, (b) after the stabilization of CNTs using
EDTA, and (c) dispersion with SDS. As can be observed, the spectra are quite similar; they present the same characteristic bands at similar positions and not observable RBM signal that confirms the CNTs multiwall nature. Also, as the D and $G$ bands are indicative of defects and graphitic structure, respectively, the ratio between relative intensities of $D$ and $\mathrm{G}$ bands $\left(I_{\mathrm{D} / \mathrm{G}}\right)$ suggests the purity degree of CNTs. Due to the above, $I_{\mathrm{D} / \mathrm{G}}$ was estimated for our samples, and it was obtained as 0.81 for CNTs as-synthesized and 0.75 and 0.77 for CNTs after dispersion process with EDTA and SDS, respectively. This behavior might be attributed to a loss of energy on the surface of the CNTs due to the new interactions between them and the surfactant molecules. In this manner, although the better dispersion was achieved with EDTA, a greater decrease in the bands for the use of SDS, which does not necessarily mean a better result, might be explained by the presence of an excessive amount of surfactant molecules in the CNTs surface, generating a bigger loss of energy. Additionally, the interpretation of the decrease in $I_{\mathrm{D} / \mathrm{G}}$ ratio indicates a reduction of the CNTs defects.

\section{Conclusions}

In summary, we studied the formation and dispersion of CNTs following TEM, SEM, and XRD techniques as well as $\mathrm{UV}-\mathrm{Vis}$ and Raman spectroscopies. TEM analysis demonstrates the typical high packing degree of the MWCNTs obtained with the spray pyrolysis method. SEM and XRD observations indicate that the acidic treatment $\left(\mathrm{HNO}_{3} / \mathrm{HCl}\right)$ 


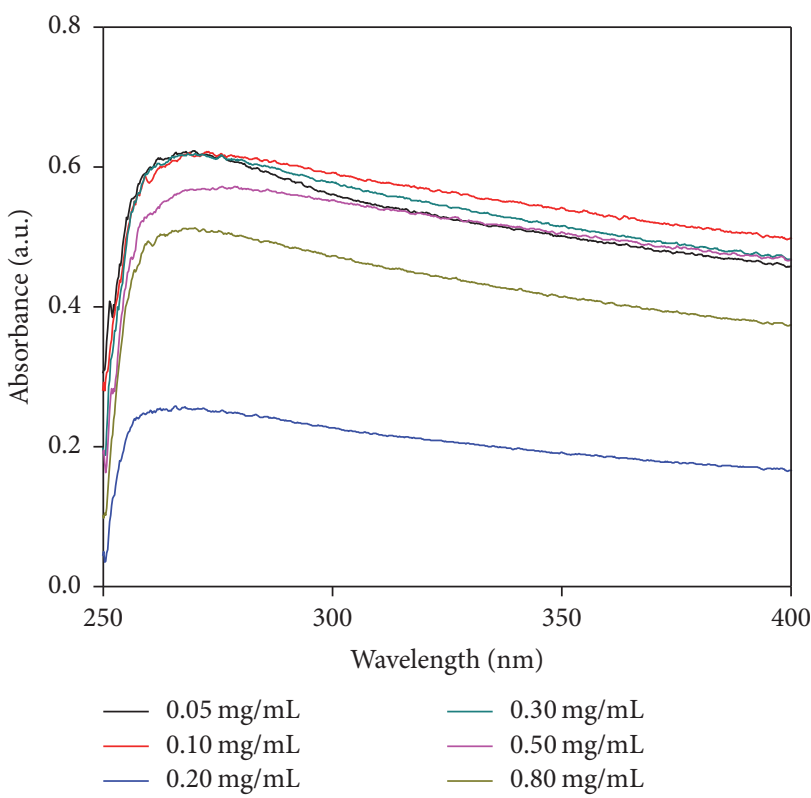

(a)

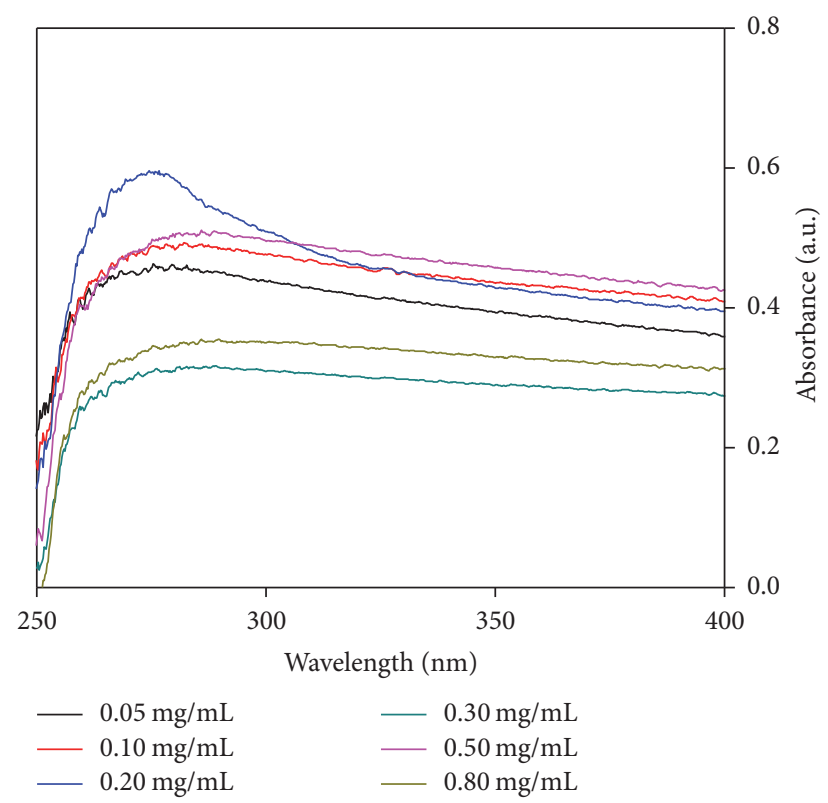

(b)

FIgURE 4: (a) UV-Vis spectra from the dispersion of CNTs using EDTA and (b) using SDS as surfactant agents.

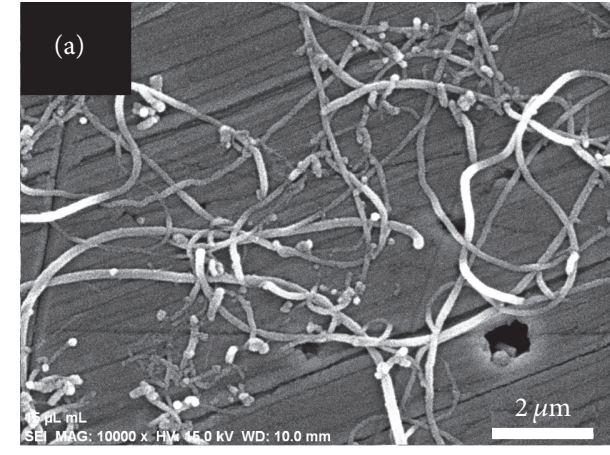

(a)

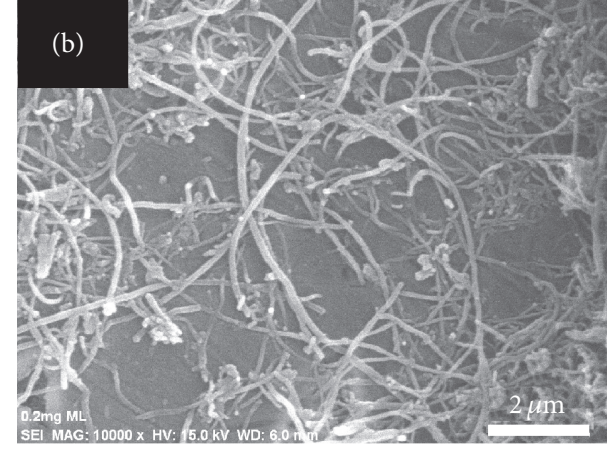

(b)

FIGURE 5: SEM images showing best concentration results from the dispersion of CNTs: (a) $0.30 \mathrm{mg} / \mathrm{mL}$ of EDTA and (b) $0.20 \mathrm{mg} / \mathrm{mL}$ of SDS.

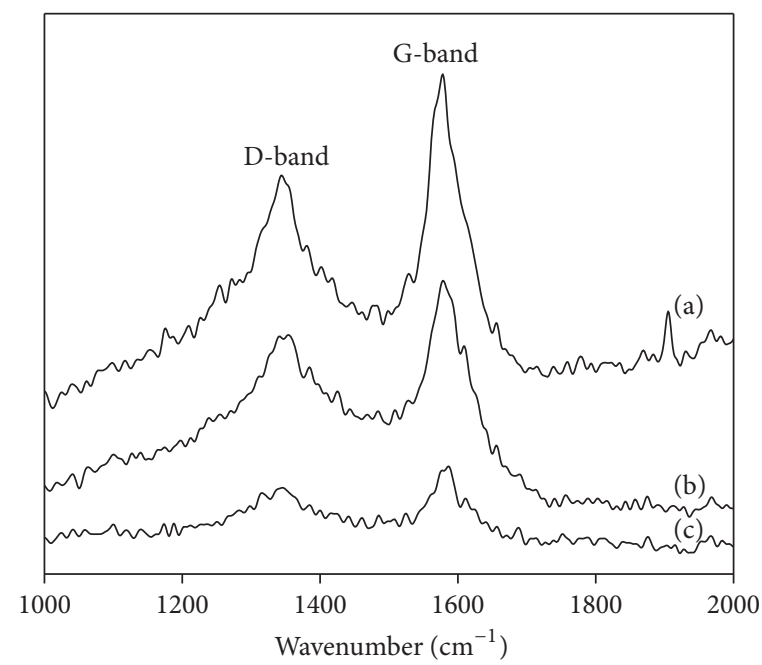

FIGURE 6: Raman spectra of the CNTs: (a) as-synthesized, (b) dispersed with EDTA, and (c) dispersed with SDS. 
increases the purity of the CNTs, especially by decreasing the Fe residual contamination particles. The purification process showed a primary tendency to deagglomerate the CNTs, helping their final dispersion. UV-Vis spectroscopy showed good results for the dispersion of CNTs when using low concentrations of EDTA and SDS as surfactant agents. However, better dispersion results are achieved with the EDTA surfactant as shown in the SEM images. Finally, Raman analysis confirms that the surfactants deagglomerate the CNTs, promoting their dispersion, by the decreasing in the $D$ and $G$ bands, which means a loss of energy because of the CNTs-surfactant interactions.

\section{Conflicts of Interest}

The authors declare that they have no conflicts of interest.

\section{References}

[1] S. Iijima, "Helical microtubules of graphitic carbon," Nature, vol. 354, no. 6348, pp. 56-58, 1991.

[2] P. J. F. Harris, "Carbon nanotube science: Synthesis, properties and applications," Carbon Nanotube Science: Synthesis, Properties and Applications, pp. 1-301, 2009.

[3] W. Ruland, A. K. Schaper, H. Hou, and A. Greiner, "Multi-wall carbon nanotubes with uniform chirality: Evidence for scroll structures," Carbon, vol. 41, no. 3, pp. 423-427, 2003.

[4] Y.-L. Zhang, P.-X. Hou, C. Liu, and H.-M. Cheng, "De-bundling of single-wall carbon nanotubes induced by an electric field during arc discharge synthesis," Carbon, vol. 74, pp. 370-373, 2014.

[5] K. S. Kim, C. T. Kingston, D. Ruth, M. Barnes, and B. Simard, "Synthesis of high quality single-walled carbon nanotubes with purity enhancement and diameter control by liquid precursor Ar-H2 plasma spraying," Chemical Engineering Journal, vol. 250, pp. 331-341, 2014.

[6] E. V. Lobiak, E. V. Shlyakhova, L. G. Bulusheva, P. E. Plyusnin, Y. V. Shubin, and A. V. Okotrub, "Ni-Mo and Co-Mo alloy nanoparticles for catalytic chemical vapor deposition synthesis of carbon nanotubes," Journal of Alloys and Compounds, vol. 621, pp. 351-356, 2015.

[7] M.-F. Yu, O. Lourie, M. J. Dyer, K. Moloni, T. F. Kelly, and R. S. Ruoff, "Strength and breaking mechanism of multiwalled carbon nanotubes under tensile load," Science, vol. 287, no. 5453, pp. 637-640, 2000.

[8] M. M. J. Treacy, T. W. Ebbesen, and J. M. Gibson, "Exceptionally high Young's modulus observed for individual carbon nanotubes," Nature, vol. 381, no. 6584, pp. 678-680, 1996.

[9] S. J. Tans, M. H. Devoret, H. Dai et al., "Individual single-wall carbon nanotubes as quantum wires," Nature, vol. 386, no. 3, pp. 474-477, 1997.

[10] P. Kim, L. Shi, A. Majumdar, and P. L. McEuen, "Thermal transport measurements of individual multiwalled nanotubes," Physical Review Letters, vol. 87, Article ID 215502, 2001.

[11] Z. Sadeghian, "Large-scale production of multi-walled carbon nanotubes by low-cost spray pyrolysis of hexane," New Carbon Materials, vol. 24, no. 1, pp. 33-38, 2009.

[12] R. A. Afre, T. Soga, T. Jimbo, M. Kumar, Y. Ando, and M. Sharon, "Growth of vertically aligned carbon nanotubes on silicon and quartz substrate by spray pyrolysis of a natural precursor: Turpentine oil," Chemical Physics Letters, vol. 414, no. 1-3, pp. 6-10, 2005.

[13] L. F. Su, J. N. Wang, F. Yu, Z. M. Sheng, H. Chang, and C. Pak, "Continuous production of single-wall carbon nanotubes by spray pyrolysis of alcohol with dissolved ferrocene," Chemical Physics Letters, vol. 420, no. 4-6, pp. 421-425, 2006.

[14] S. R. C. Vivekchand, L. M. Cele, F. L. Deepak, A. R. Raju, and A. Govindaraj, "Carbon nanotubes by nebulized spray pyrolysis," Chemical Physics Letters, vol. 386, no. 4-6, pp. 313-318, 2004.

[15] Y.-Q. Liu, X.-H. Chen, Z. Yang, Y.-X. Pu, and B. Yi, "Synthesis of aligned carbon nanotube with straight-chained alkanes by nebulization method," Transactions of Nonferrous Metals Society of China (English Edition), vol. 20, no. 6, pp. 1012-1016, 2010.

[16] L. M. Cele and N. J. Coville, "The negative effects of alcohols on carbon nanotube synthesis in a nebulised spray pyrolysis process," Carbon, vol. 47, no. 7, pp. 1824-1832, 2009.

[17] L. Huang, B. Wu, J. Chen et al., "Synthesis of single-walled carbon nanotubes by an arc-discharge method using selenium as a promoter," Carbon, vol. 49, no. 14, pp. 4792-4800, 2011.

[18] H. Qiu, Z. Shi, L. Guan et al., "High-efficient synthesis of double-walled carbon nanotubes by arc discharge method using chloride as a promoter," Carbon, vol. 44, no. 3, pp. 516-521, 2006.

[19] S.-W. Choi, J. Kim, J.-H. Lee, and Y. T. Byun, "Remarkable improvement of CO-sensing performances in single-walled carbon nanotubes due to modification of the conducting channel by functionalization of Au nanoparticles," Sensors and Actuators, B: Chemical, vol. 232, pp. 625-632, 2016.

[20] M. Eguílaz, A. Gutiérrez, F. Gutierrez et al., "Covalent functionalization of single-walled carbon nanotubes with polytyrosine: Characterization and analytical applications for the sensitive quantification of polyphenols," Analytica Chimica Acta, vol. 909, pp. 51-59, 2016.

[21] B. Thirumalraj, S. Palanisamy, S.-M. Chen, and D.-H. Zhao, "Amperometric detection of nitrite in water samples by use of electrodes consisting of palladium-nanoparticle-functionalized multi-walled carbon nanotubes," Journal of Colloid and Interface Science, vol. 478, pp. 413-420, 2016.

[22] S. Taghavi, A. H. Nia, K. Abnous, and M. Ramezani, "Polyethylenimine-functionalized carbon nanotubes tagged with AS1411 aptamer for combination gene and drug delivery into human gastric cancer cells," International Journal of Pharmaceutics, vol. 516, pp. 301-312, 2016.

[23] D. Qian, E. C. Dickey, R. Andrews, and T. Rantell, "Load transfer and deformation mechanisms in carbon nanotube-polystyrene composites," Applied Physics Letters, vol. 76, no. 20, pp. 28682870, 2000.

[24] R. Z. Ma, J. Wu, B. Q. Wei, J. Liang, and D. H. Wu, "Processing and properties of carbon nanotubes-nano-SiC ceramic," Journal of Materials Science, vol. 33, no. 21, pp. 5243-5246, 1998.

[25] S.-Y. Liu, F.-P. Gao, Q.-Y. Zhang, X. Zhu, and W.-Z. Li, "Fabrication of carbon nanotubes reinforced AZ91D composites by ultrasonic processing," Transactions of Nonferrous Metals Society of China (English Edition), vol. 20, no. 7, pp. 1222-1227, 2010.

[26] D. Mendoza-Cachú, C. Mercado-Zúñiga, and G. Rosas, "Influence of surfactant nature on the stability of carbon nanotubes synthesized by a spray pyrolysis method," in Proceedings of the 25॰ International Materials Research Congress, Cancún, México, August 2017.

[27] R. Andrews, D. Jacques, A. M. Rao et al., "Continuous production of aligned carbon nanotubes: a step closer to commercial 
realization," Chemical Physics Letters, vol. 303, no. 5-6, pp. 467474, 1999.

[28] L. Lin, H. Peng, and G. Ding, "Dispersion stability of multiwalled carbon nanotubes in refrigerant with addition of surfactant," Applied Thermal Engineering, vol. 91, pp. 163-171, 2015.

[29] M. J. Rosen and J. T. Kunjappu, Surfactants and interfacial phenomena, John Wiley \& Sons, 4th edition, 2012.

[30] I. Madni, C.-Y. Hwang, S.-D. Park, Y.-H. Choa, and H.-T. Kim, "Mixed surfactant system for stable suspension of multiwalled carbon nanotubes," Colloids and Surfaces A: Physicochemical and Engineering Aspects, vol. 358, no. 1-3, pp. 101-107, 2010. 

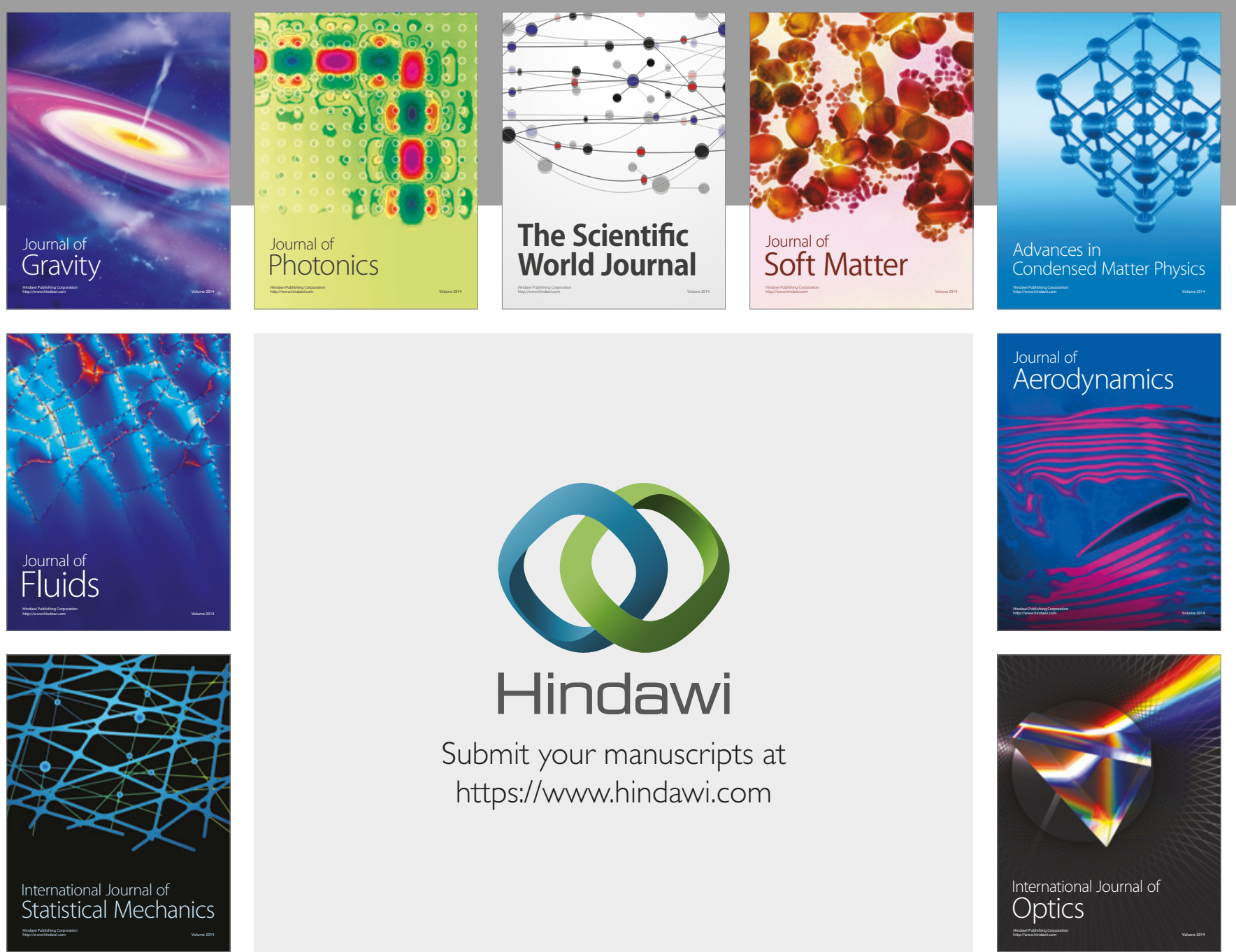

Submit your manuscripts at

https://www.hindawi.com
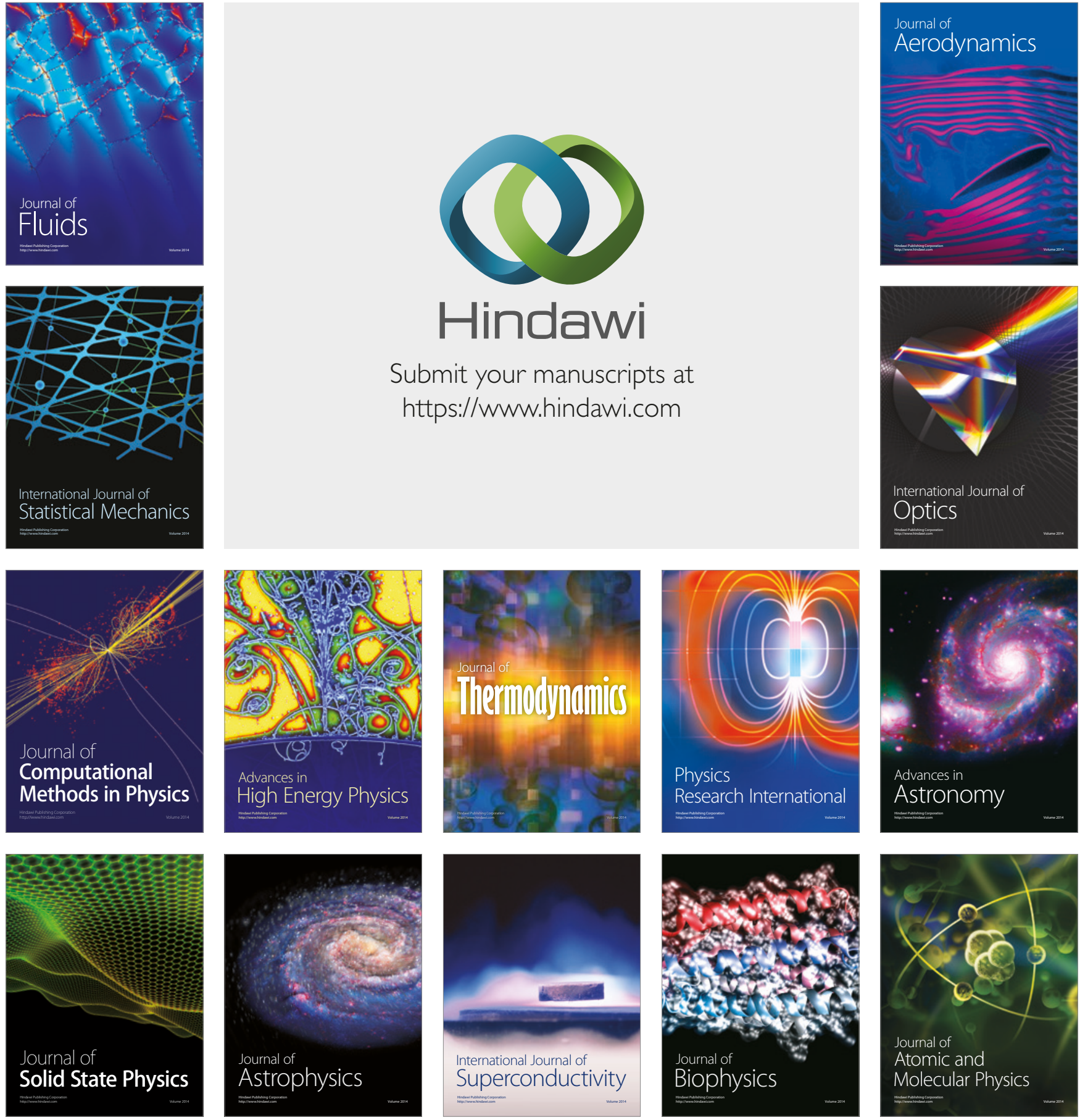